\title{
Interview
}

\author{
Interviewed by Chris R. Bell ${ }^{1}$ \\ University of West Georgia, Carrollton, GA
}

\section{Three Approaches to Psychical Reality: An Interview with Dr. Antoine Mooij}

During the fall of 2012, my first semester in the newly developed doctoral program Psychology: Consciousness and Society at University of West Georgia, I happened upon a remarkable book that was to become a continuing source of inspiration and guidance for my studies in psychology pursued as a human science - Antoine Mooij's Psychiatry as a Human Science: Phenomenological, Hermeneutical and Lacanian Perspectives. Human science psychology emphasizes the centrality and irreducibility of psychical reality, of first person subjective experience, even as it recognizes its overdetermined character in the multiple causal networks of evolving nature and culture. As I was becoming acquainted with the diverse methodological approaches to accessing this psychical reality in my coursework, I was very often left with the impression that these approaches were characterized by irreconcilable differences in both philosophical commitments and rhetorical styles, and that an integrative approach combining the best of the human science traditions was neither possible nor desirable. Antoine Mooij's Psychiatry as a Human Science demonstrated to me without a doubt that an integrative approach involving three of the most historically important human science traditions phenomenology, hermeneutics, and Lacanian psychoanalysis - was not only possible, but indeed unexpectedly illuminating, as each approach built upon and presupposed the others in an almost dialectical fashion. Experience, meaning, and reflexively accounting for the formal effects of language on what Lacan would eventually call parlêtre, or speaking-being, constitute three moments of an atemporal unity, each of them distinct, but none of which can be thought without the others. I contacted Dr. Mooij in the fall of ' 14 proposing the idea of an interview by email. He very kindly accepted this offer, and I posed to him some of the questions that had been foremost in my mind while reading his work. Perhaps my greatest curiosity of all was why a psychiatrist would be interested in psychical reality in the first place, given modern psychiatry's increasing disregard of the subjective dimension in favor of objective neurophysiological explanations and interventions. This interest indeed had to do with Dr. Mooij's own life history, professional training and background, something of which he graciously shares in our following correspondence.

Chris Bell (CB): Two of your books have recently been published in English, Intentionality, Desire, Responsibility by Brill and Psychiatry as a Human Science: Phenomenological, Hermeneutical and Lacanian Perspectives by Rodopi. Both of these studies are notable for emphasizing a human sciences approach to the psychological

\footnotetext{
${ }^{1}$ Correspondence concerning this article should be addressed to Christopher R. Bell, Department of Psychology, University of West Georgia, 1601 Maple St., Carrollton, GA, 30118, USA. E-mail: chrisramonbell@gmail.com
} 
subject, or the experiencing person, in the fields of Law and Psychiatry. Such an approach may be considered non-obvious in an era that prizes the utility of natural science. Why is a human science approach important for these fields today?

Antoine Mooij (AM): Before answering the questions I would first like to speak about myself. I studied medicine and philosophy, but during that time I already wanted to be a psychiatrist. The education in philosophy (rather classical) has helped me tremendously in psychiatry. I trained as a psychoanalyst, wrote a thesis about Lacan, which introduced Lacan in the Netherlands. The book (Taal en Verlangen, Language and Desire, 1975) has been the first introduction to Lacan's philosophy for a long time, both in the Netherlands and in Belgium. Back then I also met Lacan, and spoke with many Lacanians. However, I have always avoided Lacanian institutions. In the Netherlands some tact is necessary when speaking about Lacan; in general people are rejective (it is different in Belgium). I have also done a lot of work in the fields of phenomenology and hermeneutics; in the Netherlands these are traditionally incorporated in philosophy, but also in early psychiatry (Rümke). I have been working as a psychoanalyst, psychotherapist, and in addition to that I was director of a forensic psychiatric clinic, the observation clinic of the Ministry of Justice, which focuses on the determination of criminal responsibility (Pieter Baan Center). I was there to supervise the diagnoses, which then fed my interest in personality disorders. I've gained a lot of experience. I also taught psychopathology to law students and philosophical anthropology to students in philosophy (respectively as a professor and an honorary professor). Summing it up: there are a lot of connections in my work, because I find that opposites are often magnified in academic discussions. The contradictions are there, but they are not always as great as they are made out to be.

CB: Can you share a bit about your own history and intellectual trajectory? How is it that a medically trained Psychiatrist could become a defender of a decidedly non-medical approach to psychological subjectivity?

AM: Secondly: But doing all that I do choose for psychic reality. The biological aspect is also important for psychopathology, but in my opinion that importance is being overrated. Speaking in computer terms, I think the problem is often not to be found in the hardware, but in the input (as a result of which the hardware is disrupted, this is why psychopharmacology can be very useful). Certainly, I consider psychopharmacology an important asset. The way it is used nowadays is a different question. Anyway, the psychopathology of today is in imbalance. Moreover, the unilateral orientation on biology has not brought much gain for the practice (especially regarding medication). But it seems a little more balance is growing. It is moving towards both nature and nurture.

CB: In Psychiatry As a Human Science you provide a unique account of space and time orientations of clinical subject positions in Lacanian psychoanalysis. Can you speak to how you arrived at this compelling analysis?

AM: Thirdly: within the realm of psychic reality I am choosing for an integrative approach, not as a primary goal, but as a result of the determination of one-sidedness and parallels. A deficient me, moi, (schizophrenia) in Lacan's thinking, does not differ much from an ipseity-disorder (Sass) or a deficiency of the anti-predicative atmosphere (Blankenberg). Through the anthropological psychiatry I have encountered the importance of time, and through Binswanger the importance of time and space. I tried to insert that into the Lacanian scheme (which I have also varied and which in my opinion 
corresponds a lot with the classical nosology). To my surprise, this turned out to fit quite well. Certainly regarding phobia, which is largely a space problem: not daring to take up space (this is reflected also in the German word Angst, angustia, narrow space). And although some anticipatory anxiety is always present, time is mainly the near future and the danger threatening there, right now, coming from the outside (hence the panic). This is different from compulsions. Here the danger comes primarily from within (primarily one checks him/herself) followed by an overall control of the area (through the height dimension, and living in anticipation). As a side note, I am thinking of the compulsive personality (OCPD), not so much of the pure OC disorders. At any rate, I consider this psychopathological scheme as a supplement to the classifying diagnostics: finding out where the problem of the person concerned lies, for the purpose of a structural diagnosis.

CB: In what ways has your work as a forensic psychiatrist influenced your theoretical perspective on psychopathology? Did your interest in forensic psychiatry predate your interest in psychoanalysis, or rather did your interest in psychoanalysis lead you to work as a forensic psychiatrist? What research areas or questions do you see as remaining outstanding or requiring further elucidation for the field of forensic psychiatry?

AM: In forensic psychiatry the question of responsibility, criminal responsibility, is central. Obviously, in different legal systems (and states) this is interpreted differently; in the Anglo-Saxon world it often takes the form of the insanity defense. Specifically, this is often a cognitive interpretation of the McNaghten-rule: a defect of reason, in the sense of not knowing the nature and quality of the act one is doing. This rule can be applied well to psychotic disorders, in which cases the insanity defense is sometimes accepted. In these cases the DSM-IV/V system can be used. There must be a causal link between the disorder, a mental state, and the offense (see the McNaghten-rule). However: in Europe and in the UK, the category of diminished responsibility is also applied (diminished responsibility). This is also used in some states of the US (to determine the criminal sentence). Often personality disorders are the issue. In these cases the transition from the DSM-IV/V cannot be made directly, as personality disorders do not describe a mental state at a precise moment; instead they describe a habit, a disposition. If anyone wants to decide on diminished responsibility, they would have to form an opinion on the mental state of the moment, to make a situational analysis, and to make a structural analysis of the person. The DSM-IV/V axis II does not offer a structural outline, therefore a DSM diagnosis must always be complemented by structural consideration (and a life history). In other words, forensic psychiatry has shown me the special importance of structural psychopathology (such as Lacan's). Psychoanalysis has thus strongly influenced my vision of forensic psychiatry. (NOTE: The therapeutic efforts are independent from the forensic evaluation: these could involve medication, behavioral therapy, and possibly psychodynamic psychotherapy.) My interest in psychoanalysis thus preceded that in forensic psychiatry. It came first. But forensic psychiatry has offered me the opportunity to bring hermeneutical psychiatry into practice. That is why forensic psychiatry appealed to me: it offered the possibility of providing a very nuanced diagnosis that does not get stuck on the DSM level. It is difficult to say what the future will bring in terms of research. Definitely it is important to indicate the constraints of the predictive value of the current risk-evaluations (HCR etc). They may be valuable at a group level, but not necessarily at the individual level. Conceptual work is still needed: including that related to criminal responsibility. 
CB: You mentioned that through your work in forensic psychiatry, you developed a particular interest in personality disorders, which constitute types of subjectivity that, from a psychoanalytic perspective, are neither classically neurotic nor psychotic. It would seem that psychoanalysis has had more difficulty with establishing the coordinates of this type of subjectivity than psychiatry, which addresses the condition on the basis of a spectrum or continuum. What do you feel has aided your work, either theoretically or practically, in conceptualizing this category?

AM: I always have had an interest in personality disorders (see above). It is true that psychoanalysis offers little in this regard (exceptions: Kohut, Kernberg). Lacan offers nothing at all. In my book I am especially trying to conceptualize personality disorders from a Lacanian perspective (Lacan did not do this, and the Lacanians often do not either). I do so by limiting them to three, with perversion (now seen as a personality disorder) as the core, and the variations, the modulations thereof, in the borderline and narcissistic positions. Splitting, or disavowal, is the central concept.

CB: On a more pragmatic level, how would you describe the daily routine of your work as a forensic psychiatrist, psychoanalyst, and academic? When do you do your work? Where do you do it?

AM: do not work anymore, I am retired. I worked half-time as director of the forensic psychiatric clinic of the Ministry of Justice (responsible for reporting), half-time as a psychoanalyst and psychoanalytic psychotherapist, and was a professor for one day per week. The last ten years I have no longer worked as a psychoanalyst, but only as a psychoanalytic therapist, and I was a professor for two days a week.

CB: What have been some influential books for you?

AM: Books, that's a tough question. Influential: Lacan, Ecrits; Thomas Mann.

CB: You mentioned that you are writing a book comparing the neo-Kantian philosopher Ernest Cassirer with Lacan. Can you speak about why you were inspired to carry out this project? What do you see as the similarities between Cassirer and Lacan's thought? What do you think each author may be able to add to the other's perspective?

AM: Cassirer and Lacan have completely different backgrounds (Kant, Freud), but Cassirer shows that Kant's thought anticipates a theory of symbolization and Lacan shows that Freud's thinking leads to a theory of symbolization. First agreement: symbolization is not duplication. We represent being, the real, but in such a way that it creates a world. Being itself, the real, which Lacan also calls the "Jouissance" is closed shut. Casssirer says exactly that. Second agreement: symbolizations form a system, systems (like: language, justice). Cassirer speaks of symbolic forms (language, myths, justice). Lacan combines these symbolic forms to what he calls: symbolic order. However, there are three major differences. First point of difference. With Lacan this symbolic order comes from the outside, and forces its terminology, images, ways of interpretation and regime onto the subject from the outside. At first that subject is thereby alienated by the qualifications forced onto him from the outside (je est un autre). Only secondarily the subject may be able to relate to it: am I what they say I am or should be; but what do I want myself? This conflict is not presented by Cassirer. Second point of difference. Cassirer works from the concept of meaning (signification), so everything 
eventually can be summarized in a certain sense. Lacan works from the concept of the signifier, which makes just such a synthesis impossible. Third point of difference. Lacan, especially the late Lacan, tends to substantialize (the Real). Here Cassirer is able to correct Lacan. What is the point of this? The comparison may help to better understand Lacan, bring him closer, but can also help to correct a certain one-sidedness of Lacan (especially of the late Lacan). It is useful to place Lacan in a broad context, from which he himself has been drawing. Then it shows that Lacan does not offer a closed system, but is open to, and may be connected with other traditions (as I have tried to show in Psychiatry as a Human Science). Also he can be connected to DSM IV/V, deepening it: structural diagnostics as an addition to a classifying diagnostics.

CB: Do you feel that the emergence of social media and the increasing technological mediation of communication have lead to distinct types of psychopathology, or simply exacerbated previously known types of psychopathology?

AM: I believe that the development of social media gives rise to a worsening and increase in certain disorders (in the spectrum of the personality disorders), but not to new types of disorders (as has been suggested). The importance of the image and the virtual accessibility of everything and everyone, the decline of authority, do have consequences for the nature of modern subjectivity. That leads to a greater prevalence of narcissistic and borderline issues. The system does not specifically change. A structural approach constitutes an internal system that transcends time. A different time leads to a different prevalence, but not to a different system.

CB: What do you see as the future outlook for talk therapies in general and psychoanalysis in particular? Relatedly, what are your thoughts on psychotherapies such as the Open Dialogue form of psychotherapy originating from Finland, that attempts to eschew a dyadic clinical encounter in favor of a more guided group-oriented / social approach to crisis intervention and psychological well-being? What do you see as the benefits and drawbacks to this approach?

AM: I'm basically open to all forms of psychotherapy (certainly CBT). Psychoanalytic psychotherapy and psychoanalysis definitely have a limited scope (requires being open to the inner life, some reflection). The importance of a psychoanalytic perspective is always and first of all a careful examination: what is the relationship with the parents, guardians, what are the forces someone grew up in, what is his place in the whole, how does he place himself in life now (position of the subject)? For that kind of research, that type of treatment, a dynamic approach would be better I think. But I do not want to be dogmatic.

CB: What advice do you have for people interested in psychoanalysis? What would you say to skeptics?

AM: Psychoanalysis is much less strange and connects more with our own lives than we think. Culture is still permeated with a psychoanalytic sensibility (although nobody recognizes this as psychoanalytic anymore): the importance of psychological reality, of the relationship with significant others. It is a fact that nowadays in psychiatry and psychology this thought is not very strong (because they so badly want to be biological). But humankind is not only a biological being, but also a social being. And the core of the psychoanalytic vision is: how this biological, vital aspect compares to the social, cultural dimension (parents, siblings, society: the Other). 


\section{References}

Mooij, A.W.M. (1975). Taal en verlangen. Lacans theorie van de psychoanalyse. (Language and desire: Lacan's theory of psychoanalysis). Amsterdam, The Netherlands: Boom.

Mooij, A. (2010). Intentionality, desire, responsibility: A study in phenomenology, psychoanalysis and law. Leiden, Belgium: Brill.

Mooij, A. (2012). Psychiatry as a human science: Phenomenological, hermeneutical and Lacanian perspectives. Amsterdam, The Netherlands: Rodopi.

Mooij, A. (2015). In de greep van de taal. Symboliseren en betekenisgeving: Lacan en Cassirer. (In the grip of language. Symbolization and meaning: Lacan and Cassirer). Amsterdam, The Netherlands: Sjibbolet. 